\title{
ALGUMAS QUESTÓES INSPIRADAS PELAS ELEIÇÓES MUNICIPAIS DE 2016: COMENTANDO O ARTIGO DE ERICO TAVARES DE CARVALHO JUNIOR E ARI PEDRO ORO
}

Cecilia Loreto Mariz ${ }^{1}$

A política parece ser uma das dimensóes da vida social brasileira mais afetadas pela transformação do perfil religioso da população. Daí o grande número de estudos que buscam analisar a relação entre religiáo e política no Brasil, e que analisam mais especificamente, a relação entre evangélicos e política $^{2}$. Nesse período atual de intensas transformaçóes e tensóes políticas pelas quais o país passa, a cada dia há novidades que mudam alianças e configuraçóes políticas. Necessitam-se dados recentes constantemente. Portanto, é muito bem vindo o artigo de Erico Tavares de Carvalho Junior e Ari Pedro Oro com dados muito variados e ricos sobre as últimas eleiçóes municipais de 2016. A pesquisa, que o artigo apresenta, tem várias qualidades, que a destacam e a tornam muito útil para ajudar a entender essa questão no Brasil contemporâneo. Além de recentes, seus dados refletem a situação do país como todo, já que foram coletados em todas as capitais. Também os seus dados quantitativos sobre resultados eleitorais dos candidatos a prefeitos e, além disso, os dos candidatos a vereadores, que se apresentaram com uma identidade religiosa, foram complementados com dados qualitativos sobre o contexto político de cada capital, o perfil dos candidatos a prefeitos e as alianças políticas que os elegeram. Também, diferentemente da grande parte da literatura sobre religião e política, essa pesquisa, como já foi dito, não se

1 Professora de sociologia no Departamento de Ciências Sociais da Universidade do Estado do Rio de Janeiro (UERJ). Contato: marizcecilia@gmail.com

2 Nas referências bibliográficas do texto de Tavares Jr. e Oro encontra-se listada grande parte desses trabalhos. 
reduz a estudar os evangélicos, mas pela importância que esse grupo toma no campo há mais dados e reflexóes sobre ele no artigo analisado.

Em termos genéricos, identificam-se duas variedades de pesquisas sobre evangélicos na política no Brasil. A primeira se volta para atuação, agenda proposta, discursos de legisladores evangélicos, enquanto a segunda avalia desempenho eleitoral desses políticos e a possível origem dos votos que os elegeram. Somando-se a esse último tipo de pesquisa, o artigo de Erico Tavares de Carvalho Junior e Ari Pedro Oro, que estuda as eleiçóes municipais nas 26 capitais do país, se distingue da maior parte das pesquisas realizadas nesse campo que tem como foco as eleiçóes para as câmaras federais e estaduais, mas especialmente federais. Essa relativa ausência de estudos sobre desempenho eleitoral de candidatos a prefeitos e vereadores com identidade religiosa resulta numa lacuna que já tende a ser preenchida pelo presente estudo.

Como são as câmaras federais as encarregadas de legislar sobre as questóes relacionadas às agendas de grupos religiosos, em especial dos evangélicos e católicos, que se posicionam contra, por exemplo, a legalização do aborto, as eleiçóes para essas casas despertavam mais interesses de pesquisa. No entanto, a situação tem se modificado. Os evangélicos têm seus projetos para o executivo embora menos justificados pelas agendas políticas que em geral apresentam relacionadas às legislaçóes sobre família e vida moral. A prefeitura é um primeiro degrau no poder executivo e nesse sentido ganha importância também simbólica. Com efeito, eleição de prefeitos evangélicos já ocorria por muitos anos em cidades menores, mas a eleição de 2016 se destaca por conduzir um Bispo da Igreja Universal do Reino de Deus à prefeitura da ex-capital do Brasil, o Rio de Janeiro. A pesquisa de Tavares Jr. e Oro identifica também outros prefeitos evangélicos em capitais ${ }^{3}$.

3 Os autores identificam mais três, entre esses um que parece ter se tornado evangélico depois de eleito. Outro que dizem que é evangélico, mas ele próprio não afirmava isso na campanha. 
Somada à questão sobre o tipo de propostas e agenda que adotariam os candidatos ao executivo, em geral, e no caso específico a prefeitos, também pode se perguntar sobre a agenda apresentada pelos candidatos a vereadores. Um candidato a vereador não pode adotar a mesma plataforma moral de luta contra a legalização do aborto, por exemplo: não há como se colocar defendendo as mesmas bandeiras das eleiçóes federais. $\mathrm{O}$ que já foi observado e que hipóteses se colocam? Talvez esse tipo de eleição deixará mais evidente a força do simples compartilhamento de identidade religiosa, ou seja, do lema "irmão vota em irmão". Nesse caso não se precisa focar atenção no que esses candidatos propóem. Mas se a identidade seria assim importante, seria interessante se perguntar em que medida o discurso identificado por Joanildo Burity $(2015)^{4}$, por parte de políticos evangélicos, que coloca esse grupo religioso com uma minoria que precisa defender, seria acionado nas campanhas? Esse processo que o autor acima chamou de "minoritização da identidade evangélica” teria ressonância nas campanhas? Ou estariam as campanhas no nível municipal voltada para os interesses das áreas onde vivem os evangélicos que são, em geral, as mais pobres das cidades? E o que mais mobilizaria o voto evangélico? Para ter mais clareza do sentido desse voto seriam necessárias novas pesquisas tanto sobre os argumentos dos eleitores para escolher votar em um evangélico como também os argumentos da campanha para angariar votos por parte desses candidatos.

O comentário acima não deve ser de forma alguma interpretado como demanda de mais dados que deviam ter sido coletados nessa pesquisa ou apresentados no texto. O que não se criticaria nesse texto de forma alguma seria a falta de dados, muito pelo contrário. $\mathrm{O}$ artigo chama atenção pela variedade e quantidades de dados e já há dados mais do que suficientes. Disponibilizados em numerosas tabelas, os dados permitem comparaçóes de vários tipos: comparaçóes entre capitais, entre grupos religiosos, gênero, partidos. São tão numerosas as possibilidades de comparaçôes que evidentemente náo havia condiçôes de fazer todas em um único texto; os autores,

${ }^{4}$ Ver também Machado e Burity (2015), entre outros. 
então, estão oferecendo a oportunidade de novas análises a outros pesquisadores a partir dos seus dados.

A envergadura da pesquisa realizada impressiona. $O$ trabalho de coleta de dados certamente exigiu o esforço de uma equipe integrada e também muito fôlego e tempo. Essa coleta de dados já se iniciou durante a campanha eleitoral, como já mencionado acima, por todas as capitais do país para identificar os candidatos que naquelas eleiçóes adotavam uma identidade religiosa. Os autores comentam que para isso foram analisados os mais diversos tipos de material de campanha de 17 mil candidatos! Após a identificação desses candidatos, foi registrado o desempenho eleitoral de cada um; isso resultou, como já foi dito, em muitas tabelas. A proposta de realizar análises comparativas tornou essa multiplicidade de tabelas com grande quantidade de informação inevitável. Como foi dito, os autores fazem muitas comparaçóes, mas como não há como fazer todas as possíveis em um artigo, eles disponibilizaram generosamente seus dados para o leitor trabalhar sobre eles.

Entre as tabelas comparativas do texto, os autores destacam aquela que relaciona o crescimento da proporçáo de vereadores evangélicos eleitos em cada capital com a população evangélica de cada uma. Esses dados revelam que há uma tendência de correlação positiva entre as duas variáveis sustentando empiricamente que a mudança no perfil religioso da população estaria impactando as eleiçôes. Esse processo observado com evangélicos, no entanto, pode não acontecer com outras religióes, como mostra também a presente pesquisa. Como foi dito, os autores esclarecem que foi realizada uma prévia e exaustiva análise de material de propaganda eleitoral que lhes permitiu identificar em cada capital os candidatos que nas eleiçóes municipais de 2016 explicitaram a identidade religiosa durante a campanha. Dessa forma encontram, além dos candidatos evangélicos e católicos, candidatos que acionavam outras identidades, como a afrorreligiosa, a esotérica, a judaica e a espírita. No caso do espiritismo, foi encontrado apenas um candidato. O espiritismo tem crescido, como apontou o último censo no Brasil como um todo e mais fortemente em algumas capitais, mas talvez as doutrinas e 
visão de mundo dessa religião não levem esse grupo para a política como ocorreu com os evangélicos. O que sugerem é que talvez o alto percentual de espíritas tenha resultado em maior rejeição dos evangélicos.

Trazendo mais dados de pesquisa para o caso de Porto Alegre, os autores realizaram uma análise mais detalhada sobre cada um desses candidatos incluindo os que perderam as eleiçóes. A partir desse caso se pode pensar numa tendência de menor sucesso eleitoral de identidades religiosas afro-brasileiras ou esotéricas, talvez não apenas, ou não tanto, pela falta de eleitores, mas também pela multiplicação de candidatos. Em contrapartida, os católicos proporcionalmente apresentam menos candidatos e elegem mais os que concorrem, e em termos relativos, até mais do que os evangélicos. Esse relativo sucesso parece resultar da menor quantidade de candidatos, que sugere maior união, talvez fruto de uma unidade institucional ou da experiência e vivência política desse grupo religioso que historicamente tem marcado mais presença na política, tanto no Brasil e no exterior.

Queria destacar ainda três outros tipos de dados encontrados pela pesquisa que inspiram outras questóes, estimulando reflexóes sobre os possíveis rumos futuros das alianças e perfil setor evangélico na política. $\mathrm{O}$ primeiro deles é a presença de políticos que se identificam como "cristãos" de forma genérica evitando se dizerem especificamente evangélicos e tampouco católicos. Embora a quantidade dos que assumiram esse tipo de identidade (cristã) seja pequena, o simples fato do termo "cristáo" ser acionado como distinto em um campo onde se acostumou a falar de "bancadas evangélicas", já pode ser significativo em termos políticos e também religiosos. Indicaria essa identidade de fato um tipo de mobilização política distinta daquela dos que se dizem evangélicos? Estariam esses políticos procurando mobilizar a união de católicos e evangélicos, como tem feito tradicionalmente partidos europeus que se definem como "cristãos"? Qual a relação da adoção dessa identidade com as alianças entre evangélicos e católicos descritas por Maria das Dores Machado (2012) nas câmaras federais para defesa de determinada plataforma de defesa da "família" ou valores sexuais e morais? Somente seria possível saber qual o significado e motivo para assumir essa identidade com 
análise mais detalhada do contexto da candidatura, seus apoios e rede de sustentação e também uma análise do conteúdo da campanha eleitoral. Por exemplo, pode-se lembrar o ex-governador de Pernambuco Eduardo Campos, com vínculos conhecidos com o catolicismo, declarou-se, em sua campanha de 2014 à presidente do Brasil, quando fez aliança com a ex-senadora Marina Silva, "cristão". Essa declaração aparecia em especial quando perguntado sobre sua posição em relação ao aborto.

O que parece ficar claro, contudo, é que esses que se dizem "cristãos" não consideram o termo como sinônimo de protestante ou evangélico, como se fazia no passado recente. Era comum os evangélicos se reservarem o direito de serem chamados de cristãos, excluindo os católicos dessa categoria. Assim, acusavam os católicos de não serem cristãos por sua "idolatria" e outros comportamentos tidos como contrários aos ensinamentos bíblicos. Seria interessante a análise de possíveis novos significados do termo cristáo no presente contexto quando se define uma agenda política moral compartilhada por políticos evangélicos e católicos. Seria essa uma tendência que poderia redefinir o campo político levando alguns setores evangélicos para votar nesse tipo de candidatos? Outras pesquisas para averiguar a presença dessa identidade em outros pleitos eleitorais serão necessárias para saber se é uma tendência ou trata-se apenas de experiências isoladas.

O segundo dado também relevante, que interpela na mesma direção sobre alianças, é uma freqüente observação feita pelos autores em suas descriçôes sobre as alianças e estratégias de campanha que elegeram os prefeitos em cada uma das capitais. Os autores recorrentemente afirmam que os evangélicos se dividiram no apoio a tal ou qual candidato. Comentando em cada contexto que evangélicos receberam ou não apoio dos políticos evangélicos, os autores procuram mostrar como esse apoio era importante. No entanto, há um número razoável de casos que os autores se referem à divisão entre as lideranças evangélicas quanto ao candidato escolhido para ser apoiado. Há até o caso de um candidato a prefeito que apesar de sua identidade evangélica, não recebeu de todos setores evangélicos. A desunião entre as lideranças políticas evangélicas já tem sido observada e é fato 
relativamente comum. Análises de outras eleições têm mostrado isso especialmente nas eleiçóes do executivo, como foi o caso por exemplo na última presidencial de 2014. Portanto, a identidade evangélica e religiosa em geral não resulta em defesa de uma única candidatura ou plataforma. Seria essa uma tendência a crescer de que lideranças evangélicas nem sempre peçam votos para os "irmãos"? Em que contextos pode isso ocorrer?

Por outro lado, como foi dito acima, os dados desse artigo sugerem que os fiéis evangélicos parecem preferir candidatos evangélicos. Essa foi uma conclusão inferida pela correlação positiva entre alta proporção de evangélicos na população da cidade e o sucesso dos candidatos com essa identidade religiosa nas eleiçóes municipais analisadas. Assim, evangélicos tendem a votar em candidatos de sua religiáo e, para o caso deles, o lema "irmáo vota em irmáo" parece proceder. No entanto, os candidatos supostamente "irmãos" nem sempre estão unidos numa mesma coligação. O que explicaria a desunião? Seria uma questão de agenda? ou antes pessoal entre lideranças? seria uma estratégia de sempre ter evangélicos aliados ao poder executivo? Se essa desunião for uma tendência, que resultado terá em futuro próximo?

O terceiro dado, que quero destacar aqui, foi mais valorizado pelos autores do que os dois anteriores. Concordo com os autores sobre a relevância desse achado da pesquisa sobre o sucesso relativamente maior das candidaturas femininas evangélicas quando comparado ao sucesso das candidaturas femininas em geral. Para os autores, esse dado poderia se relacionar ao fato de que o campo evangélico também tem experimentado um crescimento do protagonismo feminino. Efetivamente essa observação explicaria um crescimento do número de candidaturas de mulheres evangélicas às eleiçóes que também ocorre. No entanto, o dado, que é relevante aqui, não é mais candidatas, mas maior voto proporcional nessas candidatas. Assim, esse argumento não explicaria o relativo maior sucesso das candidatas evangélicas em relação às mulheres em geral. Além do mais, sendo o feminismo maior na sociedade como um todo, por que os eleitores evangélicos votam mais em mulheres? Sugiro que podemos entender o fato das candidatas evangé- 
licas terem relativamente mais votos por ser tanto a população evangélica, como provavelmente o eleitorado evangélico, formados majoritariamente por mulheres. Assim, o eleitorado evangélico talvez seja mais feminino do que o eleitorado da sociedade mais ampla. Embora não se esteja dizendo que mulher vá sempre votar em mulher, pode se pensar em uma tendência de mulher votar mais em mulher do que faria um homem. Essa seria uma explicação alternativa para esse dado muito significativo encontrado por essa pesquisa. Outra questão para pesquisas futuras é se esse tipo de sucesso estimularia mais mulheres a se candidatarem e também a feminização se tornaria uma tendência no campo político evangélico.

Finalmente, gostaria de concluir essas reflexóes comentando a interpretação dos autores sobre o que significaria esse destacado papel da identidade religiosa nos pleitos eleitorais que ocorre atualmente no Brasil. Os autores consideram que esse tipo de relaçáo entre política e religiáo se explicaria pela força do "náo moderno" na sociedade brasileira. Identificam como não moderno o fato da maioria de seus habitantes, tal como os da América Latina em geral, serem religiosos e não secularizados. No entanto, gostaria de chamar atenção que mais do que a secularizaçáo e desencantamento em termos de atribuição de sentido à direção da vida pessoal e política, a modernidade tem sido relacionada à convivência de uma multiplicidade de valores, significados ideológicos e também identidades religiosas, cosmovisóes variadas e projetos diversos. A grande queda do catolicismo, que seria a religiosidade mais vinculada à tradição brasileira, e o início de uma sociedade plural indicariam um movimento de afastamento da tradição. Muito tem se questionado sobre o conceito "modernidade", concebido metodologicamente como "tipo ideal" ou como um projeto quase mitológico. Também se tem argumentado sobre os vários tipos de modernidade, como Maria das Dores Machado (2012) analisando a religiáo e a política no Brasil. As sociedades que são consideradas modernas em geral convivem com religióes universais e éticas e esse tipo de religião não pode deixar de tentar interferir na política e no estado pois são forçadas a isso para defender seus princípios éticos considerados válidos para toda humanidade. Países europeus considerados 
modernos, como a Alemanha e os Países Baixos, possuem partidos que se identificam como cristãos e esses são forças políticas importantes.

Votar em um candidato inspirado por seus princípios éticos-religiosos é muito distinto de defender um estado que seja gerido e absorvido por uma religião específica. A fusão entre política e religião, que ocorre em contextos considerados pré-modernos, é bem distinta da luta por parte de grupos religiosos em arena política entre vários outros grupos políticos religiosos e seculares. O que torna moderna é o fato da disputa ser regida por regras racionais legais e pelos grupos procurarem elaborar discursos com argumentos lógicos racionais e por defenderem projetos em princípio universais. Nas eleiçóes atuais nenhum grupo religioso se coloca com projeto de dominar o estado. Em suas campanhas e em atuação quando eleitos esses políticos, tal como os demais, apelam por valores éticos que consideram universais e que tentam defender racionalmente. Portanto, a opção de uma luta política via eleiçáo é uma prática mais moderna do que a usualmente adotada pela igreja católica de influenciar as instituiçóes a partir de diálogos e trocas entre autoridades eclesiais e governamentais. A assinatura de concordata entre a Igreja católica e o governo brasileiro seria em exemplo desse tipo de prática menos democrática e mais vinculada ao estilo histórico da religiáo lidar com o poder. A influência sobre o governo por parte da instituição Igreja era a prática mais usual do passado que pode ser considerada mais vinculada à tradição.

Como já tem sido mostrado por vários autores, a modernidade não extingue a religiáo nem a reduz totalmente ao espaço da vida privada. Essa redução à vida privada significaria o abandono de um projeto ético e social. Uma religiáo preocupada com igualdade e justiça social não pode escapar de se imbricar com a política. Por outro lado, a religiáo continua como sendo uma das várias identidades possíveis de se adotar em várias sociedades modernas, representando grupos de interesses. A modernidade não consegue impedir a imbricação entre religião e política, e nem nos países mais seculares, como 
os europeus. A porosidade entre religião e política é inevitável. A política, como a economia e outras esferas da vida social, perpassam a vida religiosa e a religião em princípio sempre tentará que essas dimensōes se submetam aos seus projetos e valores.

\section{REFERÊNCIAS}

BURITY, Joanildo. Políticas de minoritização religiosa e glocalizaçáo: notas para um estudo de redes religiosas de ativismo socio-político transnacional. Revista Latinoamericana de Estudios sobre Cuerpos, Emociones y Sociedad, Montevideo, ano 7, n. 18, p. 19-30, ago./nov. 2015.

MACHADO, Maria das Dores Campos; BURITY, Joanildo. A Ascensão Política dos Pentecostais no Brasil na Avaliação de Líderes Religiosos. Dados, Rio de Janeiro, v. 57, n. 3, p. 601-631, 2014. . Religiáo, Cultura e Política. Religiáo e Sociedade, Rio de Janeiro, v. 32, n. 2, p. 29-56, 2012.

Recebido em: 07/08/2017

Aprovado em: 07/08/2017 